\title{
EL INSTANTE, LA DURACIÓN Y LA PRESENCIA
}

Bruno Velázquez Delgado*

RESUMEN: Se ponen a dialogar dos de las interpretaciones más poéticas que la filosofía del siglo XX nos ha dado sobre el tiempo: la propuesta de Gaston Bachelard que tiene en "el instante" su concepto fundamental, y la idea de "la duración" bergsoniana. Esto, para demostrar que ambas intuiciones, más que contrapuestas, convergen y son complementarias, así como para profundizar dentro de ese marco en lo que Deleuze y Guattari entienden como "experiencia estética".

$$
\text { sose }
$$

\section{INSTANT, DURATION, AND PRESENCE}

ABSTRACT: In this article, we will discuss the two most poetic interpretations of time that twentieth century philosophy has provided us Gaston Bachelard's idea incorporating "the instant" as its core concept and the idea of the Bergsonian "duration." Thus, we will demonstrate that both concepts are not contradictory but convergent and complementary as well as elaborate in this framework what Deleuze and Guattari understand as "aesthetic experience."

PALABRAS CLAVE: Tiempo, devenir, memoria, obra de arte.

KEY WORDS: Time, devenir, memory, work of art.

RECEPCIÓN: 7 de mayo de 2015.

APROBACIÓN: 17 de junio de 2016.

* Profesor del Departamento de Estudios Generales, ITAM, y de la Facultad de Filosofía y Letras, UNAM. 
CITAM Derechos Reservados.

La reproducción total o parcial de este artículo se podrá hacer si el ITAM otorga la autorización previamente por escrito. 


\section{EL INSTANTE, LA DURACIÓN Y LA PRESENCIA}

\section{Memoria e instante}

\section{Pensar el instante no como el resultado} de una reducción del tiempo a su parte mínima y por ello indivisible —el instante atómico, partícula de nada_-; no como lo exiguo de un tiempo que se piensa desde las condiciones espaciales y, por ello, como un fenómeno lineal y mensurable, sino como un modo de darse la existencia y de estar en el mundo desde la inmediatez que se da en la atención a la vida: lo instantáneo como el modo operante del creador, el locus de la experiencia estética, el ahí intempestivo desde donde irrumpe la poiesis y la poesía, donde acontece la autoconfiguración de la persona como identidad presente.

"El instante, es un como si", ${ }^{1}$ una manera de experimentar la vida y el devenir fragmentando el tiempo, un como si kantiano que explica el tiempo vivido, la presencia de la persona en el mundo dividiendo el todo en partes, acontecimientos y por etapas. "[E]l instante del que no sabemos si es demasiado largo o demasiado corto para el tiempo", ${ }^{2}$ aquel instante que es eterno mientras dura, como se aprecia en las perenes y fugaces imágenes del haiku en sus 17 moras silábicas: perla del tiempo que es un modo existencial humano en el que simultáneamente se es devenir, presencia y estancia.

${ }^{1}$ María-Noel Lapoujade, La imaginación estética en la mirada de Vermeer, 2007, México, Herder, p. 276.

${ }^{2}$ Gilles Deleuze y Félix Guattari, ¿Qué es la filosofia?, 2005, Barcelona, Anagrama, p. 202. 
La experiencia del instante como temporalidad pura, sin contenido, da pie a la instantaneidad fruto de la facultad ficcional, de la imaginación memoriosa, que destila el túmulo de percepciones percibidas y procesadas en un momento dado por la mente, en aras de purificar aquello etéreo encapsulado por los datos concretos y los esquemas impuestos por la razón. Así, cual una alquimia intelectual, la mente logra separar la sensación de los moldes que la quieren definir y aprehender, emergiendo de ahí el conjunto de emociones vivas y secretas que darán color y serán la materia con la que trabajará la facultad imaginante, haciendo uso libre de ellas, en un juego de invención e innovación impredecible.

Así visto, se entiende que el instante haya sido tomado por no pocos pensadores como intrínseco al universo onírico. Sustancia de los sueños, el instante es materia prima y principal con el que se construyen las historias, pulsación rítmica de toda narrativa, materia viva que se distiende y da cohesión al decurso del relato. Los instantes son, entonces, las notas y silencios en una partitura que deviene. En su rítmico vaivén simbólico van acumulando y engarzando significados, dando lugar al sentido.

Es con estos instantes que habitan la memoria que la mente juega un juego de mezcla, combinación, interpretación y reciclaje para configurar los recuerdos y las narraciones que, entre otras cosas, dan sustancia y forma a nuestra cosmovisión y nuestra propia identidad.

En este tenor, plantea Bergson:

En primer lugar decimos que si se toma la memoria, es decir una supervivencia de las imágenes pasadas, esas imágenes se mezclarán constantemente con nuestra percepción del presente y podrán incluso sustituirla. Pues ellas no se conservan más que para volverse útiles: en todo instante completan la experiencia presente enriqueciéndola con la experiencia adquirida, y como esta va aumentando sin cesar, acabará por recubrir y sumergir a la otra. ${ }^{3}$

\footnotetext{
${ }^{3}$ Henri Bergson, Materia y memoria, 2006, Buenos Aires, Cactus, p. 77.
} 
Vemos que la memoria es para Bergson un microcosmos que resguarda los instantes que aprehendemos del tiempo vivido, impresiones de nuestras estancias que mezclamos para hacer el tejido de los recuerdos. Al aflorar en la superficie, los instantes estallan y se proyectan desde el pensamiento en la mirada interior de quien recuerda. Por ello entenderemos a estas entidades de luz, sombras y sentido como semillasinstantes que duermen, se activan y devienen dentro de la memoria-humus que los conserva y aviva alternativamente; instantes-germen que, al suspenderse del correr del tiempo y afectar con su brillo a aquello que Kant entiende como nuestro sentido interior, ${ }^{4}$ dejan a la conciencia memoriosa en suspenso sobre sí misma, contemplando las formas nuevas en que estas posibilidades instantáneas se actualizan e hilvanan los recuerdos.

Continuando con la licencia que nos da movernos en el lenguaje metafórico propio del método intuitivo ${ }^{5}$ - que aquí hemos retomado de Bergson y Bachelard mismos - , diremos que la memoria es amante del instante en tanto que este la complementa y despierta en ella el deseo de la reactualización del acto hermenéutico que es la remembranza y que a su vez puede ser entendido como un juego erótico de pérdida y ganancia constante, de búsqueda de sentido donde, en ocasiones, se hace posible que emerja la belleza, ${ }^{6}$ un juego de enamoramiento que tiene sus dos momentos dialécticos antes de la síntesis del recuerdo presente en el olvido y la retención. La memoria, desde su parte activa y consciente mediante la que prestamos atención a la vida presente, abraza al instante, lo recubre y complementa con otras imágenes-recuerdos y así lo separa, momentáneamente, de sus fondos indistintos y oceánicos — lo que para algunos sería el inconscientepara llevar a cabo su re-configuración: dotar a esta entidad de una nueva significación para generar y actualizar las narraciones que dan sentido a la remembranza. Es por este proceso que se entiende a la memoria

${ }^{4}$ Cfr. Immanuel Kant, "Estética trascendental", en Crítica de la razón pura, 1973, Buenos Aires, Losada, trad. de José del Perojo, pp. 297-300.

${ }^{5}$ Para una mayor comprensión del método intuitivo bergsoniano, véase Xavier Zubiri, "Bergson", en Cinco lecciones de filosofía, 2007, Madrid, Alianza; y Deleuze, "La intuición como método", en El bergsonismo, 1987, Madrid, Cátedra.

${ }^{6}$ Cfr. Platón, "Banquete", en Diálogos III, 1988, Madrid, Gredos. 
como agente de transfiguración, pues ahí se desvela una dimensión distinta del espacio-tiempo: el de la suspensión desde la duración.

La memoria va siempre acompañada, casi confundiéndose con ella, de la conciencia del instante. Para Bachelard, que aun va más lejos en este sentido, "la conciencia del instante es la conciencia" y la conciencia, así, no sería sino la atención a la vida, pura actividad presente carente de extensión temporal, lo que desde una lectura precipitada podría generar una idea similar a la que el empirismo de Hume produce en el neurólogo Oliver Sacks que, al describir en uno de sus estudios un caso grave de amnesia, se pregunta: “¿había profundidades en aquel hombre desmemoriado, profundidades con una continuidad de pensamiento y de sentimiento, o había quedado reducido a una especie de estupidez 'humeana', una mera sucesión de impresiones y acontecimientos desconectados?".

Hemos dicho que la memoria aísla al instante del contexto fluido en el que se desarrollan las circunstancias; que lo toma separándolo del torrente temporal — que aquí entendemos como Nietzsche entiende al "devenir" o, más puntualmente, como el élan bergsoniano_-, 9 que lo percibe y lo persigue porque se ve atraída de forma inevitable por

${ }^{7}$ Gaston Bachelard, La intuición del instante, 2002, México, FCE, p. 46.

${ }^{8}$ Sacks, "El marinero perdido (1)", en El hombre que confundió a su mujer con un sombrero, 2008, Barcelona, Anagrama, p. 44.

${ }^{9}$ Para Bergson, el élan vital sería la fuerza motriz de la evolución natural (biológica y cósmica: evolución creadora), aquello que vivifica la materia y los organismos, la energía que es sustancia de la persona en su dimensión mnémico-biológica así como de la Naturaleza que por ella adquiere su cualidad dinámica y evolutiva. La característica primordial de este élan vital es el acaecer de la novedad en la esfera material de lo ente, la repetición de la diferencia, la trasformación continua y multidireccional. Por ello el evolucionismo en Bergson se distingue de la idea de evolución en Hegel (que se constriñe al ámbito del Espíritu [por ejemplo, "El curso de la historia Universal", en Lecciones sobre la filosofía de la historia universal, 1953, Madrid, Revista de Occidente, trad. de José Gaos]) y de la teoría evolutiva de Darwin en su modelo lineal. Por esto, en el estudio de la teoría de la evolución creadora bergsoniana hay que poner atención a su adjetivación poiética, a su carácter, además de durable, creativo. De ahí que la condición para que se dé la evolución, para que ocurra la vida y la novedad, es el cambio constante, sin fin ni finalidad específica, y por ello Bergson entenderá la realidad, más que como "lo dado", como un "continuum" que deviene. Bergson, La evolución creadora, 2007, Buenos Aires, Cactus. 
esa excepcionalidad suya de ser "la concentración máxima de todas las fuerzas, instante que anuncia el estallido". ${ }^{10}$

El instante, entonces, es una gota de tiempo, y en esa gota - representado efectivamente-, el océano todo de la duración. La memoria es un bajel, el navío con el que a veces alcanzamos puerto y a veces naufragamos; la embarcación que somos, tripulada por la conciencia, la memoria y el olvido.

Como gota, el instante en su transparencia invierte lo que a través de él se mira, filtra lo que la memoria, en un esfuerzo de introyección, obtiene de lo real percibido atravesándolo con sus experiencias pasadas. Pero el instante es también superficie que refleja, espejo oval que distorsiona hasta la elongación más inverosímil lo que sobre él se proyecta, y es quizá debido a esta cualidad que también se ha pensado al instante como una perla:

La perla, ese núcleo vivo recoge la vida del todo.

La perla, ínfima gota del universo.

En el mar la perla es punto

Es quantum, espejo, reflejo, vida. ${ }^{11}$

El instante sería la perla que, paciente, se ha formado alrededor de una partícula de tiempo vivido, de una experiencia significativa. La historia de nuestras vidas: un collar de perlas engarzadas por amor - y el amor es siempre una fatalidad elegida - , porque "Cuando la perla ama, ella no se quiere sola; entonces, se vuelve collar". ${ }^{12}$

\section{Suspensión y duración}

Haciendo caso a Bachelard comprenderemos que "El tiempo no corre. Brota". ${ }^{13}$ Y este brotar sería el del instante intempestivo en clave nietzscheana, suspensión espacio-temporal del devenir. En el instante el

\footnotetext{
${ }^{10}$ Lapoujade, op. cit., p. 89.

${ }^{11}$ Ibid., p. 279.

${ }^{12}$ Ibid., p. 278.

${ }^{13}$ Bachelard, op. cit., p. 96.
} 
devenir propio se pone en suspenso, en un estado simultáneo de ingravidez, vértigo y gravidez donde las fuerzas se perciben, diáfanas, en su ritmo de ocultamiento y mostración. El tiempo, entendido como Bachelard, pareciera no poder ser movimiento, no tener la cualidad de durar, de ser un instante que al acontecer no hace un recorrido. En pocas palabras, instante que se contrapondría a la duración ya que la suspende, algo así como el tiempo mítico suspende el tiempo profano en Mircea Eliade. Visto así, no sería muy atrevido pensar al instante como el arquetipo que se repite y al tiempo como aquel eterno retorno de la diferencia del instante. Un instante así anularía de forma periódica la historia, dislocaría la duración y se convertiría en algo parecido a "la sustancia" del tiempo, en el elemento preciso y precioso que, en su brotar, sería la condición necesaria de posibilidad de la mismísima regeneración del tiempo. ${ }^{14}$

Mas la intuición que nos motiva no nos permite aceptar lo anterior del todo. Tras adentrarnos en el discurso bachelardiano se va descubriendo algo que después justificará nuestra convicción: que al instante también se le puede pensar de otro modo, que tras reflexionar sobre él, siguiendo la voz de Bachelard, es igualmente pertinente interpretarlo como una forma de darse el tiempo que, aunque intempestiva, rítmica e instantánea, este tiempo que brota también dura y resuena. ¿Dónde? En la persona concreta, en la conciencia sumergida y atravesada por un tiempo que, como hemos visto, simultáneamente amalgama y fractura nuestra percepción de lo real vivido.

Fragmento del tiempo vivido, el instante para Bachelard se da porque el tiempo-devenir que es el río heraclíteo, que corre y fluye sin ser nunca el mismo, siendo de este modo siempre río idéntico-a-sí debido a su constante e intrínseco diferenciar-se, ${ }^{15}$ también se nutre de fuentes

${ }^{14}$ Véase Eliade, El mito del eterno retorno, 2011, Madrid, Alianza. No es que Eliade proponga explícitamente lo arriba manifiesto. Simplemente hacemos un cruzamiento de algunas de sus ideas con otras tantas de Bachelard, con la finalidad de enriquecer el punto de vista empleado, y para señalar, desde otra perspectiva, la complejidad del problema tratado.

${ }^{15}$ Idea que es afín no solo al pensamiento de Bergson y todo el vitalismo, pasando por el pensamiento evolucionista, sino que incluye la idea del "devenir" en Hegel que, siendo la suma dialéctica del ser y el no-ser, es así el modo de darse la existencia; W. F. Hegel, "Primera sección de la lógica", en Enciclopedia de las ciencias filosóficas, 1977, México, Porrúa. 
subterráneas que en su recorrido lo alimentan y que acontecen brotando. Para pensarlo y apresarlo, para expresar lo inefable del instante, Bachelard se sirve de la poesía pues esta, según nos dice, es "una metafísica del instante". ${ }^{16}$ En Bachelard, el poema inmoviliza a la vida en el instante (como ya hemos visto que sucede en el haiku), hace la instantánea — para hablar desde la metáfora cinematográfica tan preciada por Bergson y luego por Deleuze - , realiza un retrato fotográfico imposible (por ser multinivel y polienfocado) que aísla y recrea el momento/experiencia, y es por esto que el poema-instante vendría a ser más que la vida, un concentrado de vida: pequeña muestra de totalidad.

El tiempo solo tiene una realidad, la del instante. En otras palabras, el tiempo es una realidad afianzada en el instante y suspendida entre dos nadas. No hay duda de que el tiempo podrá renacer, pero antes tendrá que morir. No podrá transportar su ser de uno a otro instante para hacer de él una duración. Ya el instante es soledad [...] Es la soledad más desnuda en su valor metafísico [...] violencia creadora [...] el tiempo limitado al instante nos aísla no solo de los demás, sino también de nosotros mismos, puesto que rompe con nuestro más caro pasado. ${ }^{17}$

El instante, entonces, entendido como una dimensión particular que se abre mediante una irrupción violenta, una espacialidad que nos sitúa al centro de una esfera que se anuncia hermética e impermeable; tiempo espacializado no al modo de la escuela eleática que en las paradojas de Zenón (donde se niegan la existencia del movimiento y a la pluralidad del ser) tiene uno de sus puntos culminantes, ${ }^{18}$ pues este no es mensurable en términos de extensión sino solo de intensidad. Pero tiempo espacializado al fin y al cabo pues se abre como dimensión indefinible que acaece de la fractura temporal que es el instante y que de este modo se presenta como un no-lugar-sin referente en la memoriaaislado y de presencia fulminante. ¿Terreno vacuo o más bien un corazón oscuro lleno de fertilidad nocturna, como el interior de la semilla que

${ }^{16}$ Bachelard, op. cit., p. 19.

${ }^{17}$ Ibid., p. 11.

${ }^{18}$ Cfr. Diógenes Laercio, "Zenón de Elea", en Vidas, opiniones y sentencias de los filósofos más ilustres, 1984, México, Porrúa; y G. Colli, Zenón de Elea, 2006, México, Sexto Piso. 
es toda potencia y aún nada en acto fuera de su ser semilla? El instante es una nueva dimensión que, para colmo, pareciera poner a prueba la realidad.

Desde esta perspectiva, y a primera vista, el instante en poco se parece al silencioso y líquido brotar antes propuesto; quizá solo en la intimidad que abre y en su efecto de afección sobre quien lo experimenta. Pareciera, en esta presunta incoherencia, que Bachelard se toma muchas licencias, cayendo incluso en discordancias discursivas al dar rienda suelta a su sin duda bello manejo de la metáfora. Pero, aunque parezca improbable, la propuesta bachelardiana vuelve a girar sobre su gozne, llegando incluso, si no a afirmar sí a no negar la posibilidad de que el instante tenga, en el fondo, un tipo de duración. Lo que se sigue, puntualmente, de la identidad que hace entre el presente y la vida toda, esto es, la vida extendida hacia el pasado y su futuro, una identidad percibida ya por Agustín - aquí reverberada por el mismo Bachelardcuando dice:

Lo que por el momento veo con toda claridad es que no existen ni las cosas futuras ni las pretéritas. Y pienso que no se habla con propiedad cuando se dice que los tiempos son tres, pasado, presente y futuro. Más exacto me parece hablar de un presente de lo pretérito, un presente de lo presente y un presente de lo futuro; porque estas tres modalidades las encuentro en mi mente pero por otras partes no las veo. Lo que sé es que tengo una memoria presente de lo pasado, una percepción presente de lo actual, y una expectación presente de lo venidero. Si de este modo se entiende, acepto y afirmo que los tiempos son tres, pasado, presente y futuro como se dice en el uso común. ${ }^{19}$

En su debate implícito con Bergson, Bachelard intentará mostrar que, más allá de que la idea de la duración nos dirija la mirada hacia la totalidad del tiempo, hacia la plenitud de cada tiempo vivido hic et nunc, esta idea no le da su lugar ni le concede al instante una realidad decisiva. En Bergson — dice Bachelard—- la comprensión de la vida como duración y evolución creadora — como élan- puede hacernos perder

${ }^{19}$ Agustín, Confesiones, libro XI, 1997, Madrid, Biblioteca de Autores Cristianos. 
de vista el papel decisivo del instante como la irrupción del momento innovador en que surge la creación, la duración oculta, engullendo y diluyendo, al instante creador $y$, en este sentido, nos impide reconocer "el rasgo verdaderamente específico del tiempo". ${ }^{20}$

Pareciera, por lo visto, que la distancia entre entender el tiempo como sucesión de instante o devenir, como algo intempestivo, cerrado y con límites claros o como torrente, fluir continuo y duración es insalvable. Más aún si hablamos de que Bachelard también postula que la duración, de darse, solo lo haría desde el reposo pues, siendo lo contario al instante que es la condición de posibilidad del acto, la duración no podría ser sino una extensa calma en la que ningún cambio se anuncia ni puede adivinarse. Pero como es de sospecharse, no es del todo así y la distancia que separa las dos posturas termina por reducirse hasta el reencuentro que se da como siempre ha sido toda reconciliación, gracias a esa fuerza insalvable para todo pensamiento filosófico que valga: el amor.

Sabemos que lo anterior supone un salto riesgoso, sin embargo es el mismo Bachelard quien acude en nuestra ayuda al decirnos que el tiempo, instantáneo e irrupción, se prolonga en nosotros, las personas concretas, ya que amamos y sufrimos. Es decir, que el instante termina por evocar otras vivencias y esto lo expande tal y como Proust lo describe en uno de sus más famosos pasajes cuando, tras llevarse a los labios una cucharada de té en el que había echado un trozo de magdalena, el tiempo eterno lo invade todo en un instante:

Pero en el mismo instante en que aquel trago, con las migas del bollo, tocó mi paladar, me estremecí, fija mi atención en algo extraordinario que ocurría en mi interior. Un placer delicioso me invadió, me aisló, sin noción de lo que lo causaba. Y él me convirtió las vicisitudes de la vida en indiferentes, sus desastres en inofensivos y su brevedad en ilusoria, todo del mismo modo que opera el amor, llenándose de una esencia preciosa; pero, mejor dicho, esa esencia no es que estuviera en mí, es que era yo mismo. ${ }^{21}$

${ }^{20}$ Bachelard, La intuición del instante, 2002, México, FCE, p. 21.

${ }^{21}$ Marcel Proust, Por el camino de Swann, 1998, Madrid, Alianza, p. 25. 
Desde la fractura misma que es el instante se abre una fuga por donde la duración se filtra y así, la duración habita también en el instante, uno y otra han dejado de contraponerse en el entrecruzamiento desde el cual ambos se alimentan y diversifican, sin que pueda ser más uno sin la otra.

Duración e instante van de la mano en el tiempo vivido, son las dos fibras - expansivas y comprensivas - que constituyen al tiempo encarnado que es la persona, y esto ha quedado evidenciado en su naturaleza patética, pues nadie puede padecer, amar o sufrir si no es desde el instante cargado de duración, evocador e intempestivo.

La forma de darse el tiempo es, entonces,

un amor profundo [...] un ideal de armonía temporal en que el presente se ocupa sin cesar en preparar el porvenir. Es a la vez una duración, un hábito y un progreso [...] El tiempo se prolonga y dura en nosotros porque amamos y sufrimos [...] Llenamos nuestro tiempo como llenamos nuestro espacio mediante el simple cuidado que tomamos en nuestro porvenir y mediante el deseo de nuestra propia expansión. De ese modo, en nuestro corazón y nuestra razón, el ser corresponde al Universo y reclama la Eternidad. ${ }^{22}$

Es por este modo de estar en el tiempo que hay duración en tanto posibilidad de la identidad personal que tiene su base en la memoria.

Como puede verse, Bachelard introduce la noción de la eternidad sin mayor reserva para señalarnos que la experiencia del instante nos arroja, sin soltarnos del todo, ante las regiones descomunales del no-tiempo; que la fractura que se abre con la irrupción del instante nos deja suspendidos sobre el devenir, como si el instante fuese ingrávido y lograse suspendernos del fluir imperecedero.

Y entonces ya no habrá que pensar, como en un primer momento, que "la duración está hecha de instantes sin duración, como la recta de puntos sin dimensión", ${ }^{23}$ sino que el tiempo, en su infinitud, es macro y microcósmico, cauce y torrente; que si el tiempo, la vida y la persona

${ }^{22}$ Bachelard. op. cit., pp. 84-85.

${ }^{23}$ Ibid., p. 18. 
son comprendidos como duración y suma de instantes es porque dentro de la duración, dentro del instante, hay duraciones y otros tantos instantes posibles.

\section{Amor fati: instante y duración}

"El hombre, en verdad, es tiempo, brevísimo tiempo del gran tiempo."24

Dos caminos convergen aquí: nadie los ha recorrido aún hasta su final. Ese largo sendero hacia atrás: dura una eternidad. Y ese largo sendero hacia delante - es otra eternidad.

Se contraponen esos caminos; chocan derechamente de cabeza: —y aquí, en este portón, es donde convergen. El nombre del portón está escrito arriba: "Instante"

$[\ldots]$

¿Y no están todas las cosas anudadas con fuerza, de modo que este instante arrastra tras de sí todas las cosas venideras? ${ }^{25}$

Hablamos del tiempo encarnado que se da en y desde la persona, tiempo que en este caso es vida, vivencia, devenir, transformaciones, presencia y estancia, dándose todas ellas en la duración individual y concreta del ser autoconsciente que se evidencia a sí mismo mediante la atención al instante, a los pequeños brotes internos al brote externo que es su aparecer existencial.

Cuando en el andar impreciso y en la forma muchas veces desatendida en que nos manejamos en la cotidianidad — donde el tiempo corriente, la vida habitual y acostumbrada a dejarse llevar sin pausas reflexivas, se nos escapa sin que apresemos y apreciemos nuestras estancias a cabalidad-, el instante irrumpe y nos obliga a hacer un alto y a demorarnos ante su umbral, que no es sino la fractura que realiza en la experiencia cotidiana, ahí acontece la emergencia del tiempo vivido, entendido este como vivencia y como estancia. Al fin un tiempo dentro del tiempo, advertencia de la duración personal sumergida en la Duración,

${ }^{24}$ Ramón Xirau, El tiempo vivido, 1993, Madrid, Siglo XXI, p. 23.

${ }^{25}$ Friedrich Nietzsche, Asi habló Zaratustra, 2007, Madrid, Alianza, p. 230. 
desde donde podemos experimentar, comprender y afirmar el momento exacto en el que estamos, la decisión actual, el acto efectivo que se realiza desde lo que Nietzsche entiende como el amor fati: una afirmación de la totalidad de la vida y de la propia existencia realizada en cada uno de estos instantes decisivos - y decimos decisivos porque es allí donde acontece la elección, aquella que concluye nuestros procesos re-flexivos y dirige nuestro actuar.

Para Nietzsche, el amor fati es la actitud imprescindible para hacer la experiencia del eterno retorno como modelo de valoración, como la regla aurea de nuestra moral que nos dicta que todo actuar y desear ha de pasar la prueba de su repetición hipotética ad infinitum. Pero para ello antes habremos de comprender el tiempo propio, la duración que somos y los instantes que nos definen. Solo así, lo que elegimos podrá soportar la prueba de la eternidad, quererse una y mil veces, formar parte de la elaboración y conquista efímera del gran deseo: afirmar la propia vida y el conjunto de las decisiones tomadas en su curso de modo tal que se pueda desear repetirlas una y mil veces.

El amor fati es decir sí, sí al instante, sí al aquí y ahora, sí a todos los hechos en que hemos participado; amar lo hecho y lo acontecido, aceptar las causas y los efectos de nuestro paso por la Tierra como algo aceptado, decidido y asumido sin reserva. Decir sí al tiempo vivido y a la propia vida tal cual en su devenir, dirigiendo al deseo como un auriga que ha comprendido el eterno retorno de los ciclos y de la diferencia.

Pero, como se puede adivinar, para realizar este sí rotundo a lo instantáneo y a lo infinito habrá que reconocer y aceptar de buena gana la propia finitud, la condición trágica de la existencia humana ${ }^{26} \mathrm{y}$, por supuesto, la eternidad como un fruto que solo podremos entrever y añorar. Tal y como Fausto, cuando en éxtasis revela su anhelo más profundo pidiendo lo imposible, sucumbiendo a su autocondena y dando voz a una embriaguez que no puede sino exclamar con la voz tenue del que se sabe a punto de ser sacrificado: "Detente, instante, jeres tan bello!". ${ }^{27}$

${ }^{26}$ Cfr. Friedrich Nietzsche, El nacimiento de la tragedia, 2003, Madrid, Alianza.

${ }^{27}$ Goethe, Fausto, 2013, México, Debolsillo, p. 850. 
El amor fati es, entonces, amor al instante, es quererlo y aprehenderlo desde su propia duración. Momento desde donde Zaratustra nos dirá con poderosa voz, superada la derrota fáustica por una voluntad de hierro palpitante: “¿Era esto la vida? ¡Bien! ¡Otra vez!”. 28

La afirmación del instante es, como hemos visto desde distintas atalayas que van de las cimas a la sima de la vida humana - demasiado humana-, un re-conocimiento: el amor fati es decir sí para afirmar, a un tiempo, nuestro pasado, presente y futuro como devenir y abrir, en el instante, las esclusas desde donde se desata la intuición de nuestra propia duración que corre inmersa en la duración universal - la conciencia de nuestro ser gota sumergida en el tiempo oceánico.

Se ha evidenciado aquí que el instante solo se entiende cruzado por la imaginación y desde la metáfora que nos devela la organicidad de nuestro cuerpo como tiempo encarnado, como duración en la Duración. Y esto no solo por el carácter inefable del tiempo en sus múltiples formas de darse, sino porque, como cúmulo de fuerzas en juego, el instante es un tipo sui generis de espacio-temporalidad significante: sincronía y simultaneidad de reminiscencias, reverberaciones, referencias, alegorías y misterio, pero también sensibilidad, manifestación de sentimientos y estados anímicos y mentales, bloque de sensaciones y posibilidad del acaecimiento del recuerdo como narratividad.

Ficción, realidad, memoria, estancia, olvido, manifestaciones del cosmos onírico, emociones diversas y los datos de la percepción surgidos de la vigilia se mezclan en el instante reconfigurado por la atención presente. Y todos estos elementos vienen a componer lo que descubriremos como la propia duración: un todo que es más que la suma de sus partes y que se distingue, por instantes, en la indistinción del tiempo oceánico universal.

Instante indivisible pero compuesto, múltiple y fractal-rizomático pues, como dicen Deleuze y Guattari acerca del rizoma: ${ }^{29}$ Este es "una

${ }^{28}$ Nietzsche, Asi habló Zaratustra, p. 229.

${ }^{29}$ Concepto presentado por Deleuze y Guattari para referirse a un modo de ser del ente y de darse el pensamiento que, tal y como los fractales, son una unidad que se replica y forma nuevas unidades y conjuntos: conjuntos de conjuntos, organismos y sistemas complejos. Ponen 


\section{multiplicidad [...] una especie de organismo, o bien una totalidad significante", ${ }^{30}$ no una unidad con varios significados, sino multipli- cidad indivisible significante, instante-fractal-rizoma que puede ser tomado desde cualquiera de sus aristas y crecer a partir de ahí dicien- do siempre algo nuevo o repetirse al infinito. Instante tomado por la memoria y que al actualizarlo permite que se expanda, profundice}

el ejemplo del pasto como organismo rizomático al que se le puede cortar una parte y trasplantar sabiendo que se regenerará: un tipo de organismo descentrado pues cada parte es núcleo replicante:

Un rizoma como tallo subterráneo se distingue radicalmente de las raíces y de las raicillas. Los bulbos, los tubérculos, son rizomas [...] los animales lo son cuando van en manada, las ratas son rizomas. Las madrigueras lo son en todas sus funciones de hábitat, de provisión, de desplazamiento, de guarida y de ruptura. En sí mismo, el rizoma tiene formas muy diversas, desde su extensión superficial ramificada en todos los sentidos hasta sus concreciones en bulbos y tubérculos. Ahora bien, somos conscientes de que no convenceremos a nadie si no enumeramos algunos caracteres generales del rizoma. $1^{\circ}$ y $2^{\circ}$ Principios de conexión y de heterogeneidad: cualquier punto del rizoma puede ser conectado con cualquier otro, y debe serlo. Eso no sucede en el árbol ni en la raíz, que siempre fijan un punto, un orden [...] $3^{\circ}$ Principio de multiplicidad: solo cuando lo múltiple es tratado efectivamente como sustantivo, multiplicidad, deja de tener relación con lo Uno como sujeto o como objeto, como realidad natural o espiritual, como imagen y mundo. Las multiplicidades son rizomáticas y denuncian las pseudomultiplicidades arborescentes. No hay unidad que sirva de pivote en el objeto o que se divida en el sujeto. No hay unidad, ni siquiera para abortar en el objeto o para "reaparecer" en el sujeto. Una multiplicidad no tiene ni sujeto ni objeto, sino únicamente determinaciones, tamaños, dimensiones que no pueden aumentar sin que ella cambie de naturaleza (las leyes de combinación aumentan, pues, con la multiplicidad) $[\ldots] 4^{\circ}$ Principio de ruptura asignificante: frente a los cortes excesivamente significantes que separan las estructuras o atraviesan una, un rizoma puede ser roto, interrumpido en cualquier parte, pero siempre recomienza según esta o aquella de sus líneas, y según otras. Es imposible acabar con las hormigas, puesto que forman un rizoma animal que aunque se destruya en su mayor parte, no cesa de reconstituirse $[\ldots] 5^{\circ}$ y $6^{\circ}$ Principio de cartografía y de calcomanía: un rizoma no responde a ningún modelo estructural o generativo. Es ajeno a toda idea de eje genético, como también de estructura profunda [...] El árbol articula y jerarquiza calcos, los calcos son como las hojas del árbol. Muy distinto es el rizoma, mapa y no calco. Hacer el mapa y no el calco. La orquídea no reproduce el calco de la avispa, hace mapa con la avispa en el seno de un rizoma. Si el mapa se opone al calco es precisamente porque está totalmente orientado hacia una experimentación que actúa sobre lo real [...] Resumamos los caracteres principales de un rizoma: a diferencia de los árboles o de sus raíces, el rizoma conecta cualquier punto con otro punto cualquiera, cada uno de sus rasgos no remite necesariamente a rasgos de la misma naturaleza [...] El rizoma no se deja reducir ni a lo Uno ni a lo Múltiple. No es lo Uno que deviene dos, ni tampoco que devendría directamente tres, cuatro o cinco, etc. No es un múltiple que deriva de lo Uno, o al que lo Uno se añadiría $(\mathrm{n}+1)$. No está hecho de unidades, sino de dimensiones, o más bien de direcciones cambiantes. No tiene ni principio ni fin, siempre tiene un medio por el que crece y desborda [...] Una meseta no está ni al principio ni al final, siempre está en el medio. Un rizoma está hecho de mesetas. Gregory Bateson emplea la palabra "meseta" (plateau) para designar algo muy especial: una región continua de intensidades, que vibra sobre sí misma, y que se desarrolla evitando cualquier orientación hacia un punto culminante o hacia un fin exterior. Deleuze y Guattari, Rizoma, 2005, Valencia, Pretextos, pp. 10-20.

${ }^{30}$ Ibid., Rizoma, p. 10. 
y dure en nuestra conciencia ("haciendo rizoma” dirían Deleuze y Guattari).

Es en este momento en el que la persona aprehende la vida desde el instante, que se experimenta y sobrelleva un cambio existencial pues el propio modo de experimentar la realidad y la vida misma muda y se transforma. La forma distraída y disipada del tiempo cotidiano transmuta - por medio de la conciencia y aprehensión del tiempo vivido - y se hace presencia. Esto y no otra cosa será el estar: ser presencia, estar presente es "hacer estancia" en un tiempo-espacio que ya es propio. Y desde aquí es que podremos entender a la persona como alguien que, más que ser, es un estar.

\section{El estar y la presencia}

"La presencia es fundamental pero no sería posible sin nuestro estar."31 Imaginación-instante-memoria-duración son los elementos que, al relacionarse, se tornan indisociables al posibilitar la identidad personal, la estancia y la creación como poiesis de sí mismo. Vivir el instante, desde-el-instante, es para nosotros lo que hemos visto que en Agustín es la vivencia del tiempo. ${ }^{32}$ Porque estar es el existencial que refiere a la vida vivida como vivencia y no solo a un tipo entidad que está siendo-ahí arrojada en el tiempo que le es ajeno.

La vida: el tiempo vivido, la duración de nuestra identidad personal que es el tiempo en el cual la persona también se desvive y, al final, se desvanece. Un estar que es duración y devenir, fin y comienzo, cambio constante y continuidad.

Presente-pasado-futuro se enlazan en la conciencia del instante donde se funden estos tres éxtasis del tiempo en uno solo y actual. La conciencia, imaginante y memoriosa, voluntad y reflexión, teje su propia duración con las agujas del instante y se narra a sí misma continuamente.

Ya otros nos han hecho ver que la comprensión lineal del tiempo, un tiempo comprendido desde el espacio, con un "antes" y un "después",

${ }^{31}$ Xirau, op. cit., p. 12.

${ }^{32}$ Cfr. Agustín, loc. cit. 
separa y fractura a la persona, disloca a la historia de sus posibilidades al implantarle un origen forzosamente surgido de la nada y un desenlace teleológico definitivo, predeterminado. Nada más inaceptable para quien ha logrado intuir la duración, la evolución y el eterno retorno de la diferencia que son formas de darse el devenir y en él la libertad. Esto es, el modo en que se nos abre el mundo de nuevo, como posibilidad.

Desde la estancia - tiempo vivido como duración y desde el instante presente-, la persona entra en simpatía con la alteridad circundante, que es también duración, y así habita el mundo. En este modo de estar la persona no dice "yo soy", sino más bien un "yo me soy" sartreano "y me soy siendo": 33 "Estar significa, con dignidad y modestia, con humildad y orgullo, arraigar en la tierra y vivir en relación subjetiva con los otros". ${ }^{34}$

La persona se vive a sí misma, se narra su propia historia para reconstruir su identidad a imagen y semejanza de lo que ha sido y, por ello, conserva su mismidad, se refleja en el otro y reconoce su propia unicidad y dignidad en la particularidad y dignidad del rostro ajeno. La vivencia es, así, presencia, identidad y estancia. La persona: duración, cambio, simpatía y creación, por ello, permanencia y devenir. En el transcurrir del tiempo vivido la persona tiene en los instantes sus guías

24 de camino, señas de sendero que apuntalan la memoria y aseguran su frágil duración psíquico-emocional. Pero el instante ahora se ha vuelto instancia, habitación y rincón del tiempo que nos ofrece su morada.

Esta sería la geografía del instante: residencia de la persona, espacio de la duración, lugar donde se está, donde se da la presencia y emergen las estancias, donde se fractura el tiempo para restablecerse como continuum.

Ramón Xirau dice, a propósito del verso elevado por Quevedo:

En el Hoy y Mañana y Ayer junto

pañales y mortaja, y he quedado

presentes sucesiones de difunto.

Vivir es caminar breve jornada,

${ }^{33}$ Xirau, op. cit., p. 35.

${ }^{34}$ Ibid., p. 60. 
y muerte viva es, Lico, nuestra vida, ayer al frágil cuerpo amanecida, cada instante en el cuerpo sepultada.

"El presente ya no cuenta. Por dos motivos: en tanto no es, puesto que es transcurso; y en tanto no es, porque es disolución.." ${ }^{35} \mathrm{Y}$ pareciera así que Xirau se alinea con el primer Bachelard al concebir al instante como aquello a que se reduce el tiempo, pues este no sería más que una sucesión de instantes semejantes a granos de nada. Pero la voz de Xirau, que es voz de poeta, no se agota en una línea y más delante revela que habrá que entender al instante no desde lo dado, sino desde el fondo de la persona que es pura duración. "La presencia es, de nuevo, el reposo que entraña toda contemplación del cambio; el estar que lleva consigo todo transcurrir." 36

Y el sujeto es presencia porque es sujeción, sujeción a su estancia, imposibilidad de rebasar los límites de su propia presencia, imposibilidad de sobrepasarse en nulificación [...] duración que dura, es decir, que se conserva [...] El hombre está. Y estar es estar ahí, con las cosas, con los hombres, con el mundo. ${ }^{37}$

Estar es arraigarse, elevarse, vivir e imaginar a un tiempo; vivir es darse como se da el tiempo bergsoniano que es transcurrir, transformación, permanencia, evolución creadora, unidad más diferencia y, en una palabra, duración. Estar es ser presencia, un modo de ser en el tiempo siendo tiempo propio.

De la misma manera que las ondas circulares brotan del impacto de la piedra en el agua, las dimensiones del tiempo se desparraman a partir de un centro que las coordina y les presta unidad: la presencia [...] El estar nos pone en situación, nos instala, nos coloca. Nos coloca en el espacio y nos instala en el tiempo. Nos da nuestro lugar, pues es una forma de la presencia y de la perseverancia. ${ }^{38}$

${ }^{35}$ Ramón Xirau, Sentido de la presencia, 1997, México, FCE, p. 22.

${ }^{36}$ Ibid., p. 130.

${ }^{37}$ Ibid., p. 127.

${ }^{38}$ Ibid., p. 56. 
Jorge Guillén dijo: “Soy; más, estoy, respiro”. Y de este verso Xirau da a comprender que "el 'soy' estrangula y en cambio el 'estoy' respira". 39

El "ser” imposibilita al devenir. ${ }^{40 ~ " E s t a r " ~ e s ~ r e s p i r a r: ~ a s p i r a c i o ́ n ~ e ~}$ inspiración humana.

El instante dura y permanece en la memoria y allí, cambiando, reposa. En el "estar" que abre el instante vivido plenamente, la persona dura y permanece, halla un resquicio de su propia eternidad.

Apollinaire dijo la presencia, que es estancia, de manera inigualable cuando cantó: "Los días se van, yo permanezco". ${ }^{41}$

Y así, permanecemos, incluso al diluirnos, incluso deviniendo algo distinto o, como Rimbaud diría: "Yo es otro. Tanto peor para la madera que se descubre violín, iy mofa contra los inconscientes, que pontifican sobre lo que ignoran por completo!". ${ }^{42}$

En la vivencia del tiempo recobrado nos reapropiamos de nuestra duración, logramos la "estancia" desde donde habitamos el instante y conquistamos nuestros propios y efímeros relámpagos, sosegados y silenciosos, de pequeña eternidad.

Homo humus, fama fumus, finis cinis.

${ }^{39}$ Loc. cit.

${ }^{40}$ Cosa distinguida ya por Hegel, después por Nietzsche y, en sus propios términos, por Freud, que en una entrevista que le realizó George Sylvester en 1926, hace la siguiente reflexión: "Es posible que la muerte misma pueda no ser una necesidad biológica. Quizá morimos porque queremos morir. Incluso del mismo modo que el odio y el amor por la misma persona habitan en nuestro interior al mismo tiempo, la vida combina, con el deseo de mantenerse, un ambivalente deseo de su propia aniquilación. Igual que una banda de goma extensible tiene la tendencia a volver a asumir su forma original, toda materia viva, consciente o inconscientemente, anhela recobrar la completa y absoluta inercia de la existencia inorgánica. El deseo de vida y el deseo de muerte conviven lado a lado dentro de nosotros. La Muerte es la compañera del Amor. Juntos gobiernan el mundo. Este es el mensaje de mi libro Más allá del principio del placer." Cfr. <http://espaciodevenir.com/referencias/" el-valor-de-la-vida"entrevista-a-sigmund-freud-por-george-sylvester-viereck-en-1926/>, consultado el 16 de junio de 2016).

${ }^{41}$ Ibid., p. 68.

${ }^{42}$ Arthur Rimbaud, Cartas del vidente, Carta del 13 de mayo de 1871 dirigida a George Izambard, en $<$ http://www.poeticas.com.ar/cartas/cartas-del-vidente/>, consultado el 16 de junio de 2016. 


\section{Apéndice}

Pintar las fuerzas desde la estancia: Un análisis estético basado en la interpretación que Lapoujade hace de obra de Johannes Vermeer Conectar lo dicho líneas anteriores con el modo der ser de la obra de arte, desde una perspectiva estética, es tarea que hemos decidido hacer tan solo para redondear la visión propuesta. Para no extrapolarnos hemos elegido la obra de un pintor y, de este conjunto, apenas una de las muchas críticas. El pintor: Johannes Vermeer; la crítica estética: la de María Lapoujade. La razón está en la pasión concreta que siempre profesó hacia el instante Vermeer. El más silencioso pintor de la luz. ${ }^{43}$

En su obra se percibe de inmediato - además de su enamoramiento por los efectos de la luz y su exquisito talento para representarla desde el lenguaje plástico - el respetuoso amor a los instantes de la vida cotidiana; una profunda pasión por lo mínimo, por el rincón, por el pan que se desmigaja imperceptiblemente, por la gota de leche que se desprende, en su caída, del sutil torrente que se vierte, oculta, en el espacio íntimo e imperceptible de la vida privada y habitual.

La obra de Vermeer pinta "vida contenida, concentrada hasta el infinito [pinta el] secreto guardado [el] misterio encerrado en una minúscula perla, donde boga una eternidad plena: la del instante."44

La totalidad de los momentos capturados por Vermeer nos dicen, desde este otro lenguaje, lo que ya hemos visto desde la reflexión filosófica y la poesía. Y esto es que todo instante es pleno, completo, total: espacio-tiempo circular, esfera en movimiento y símbolo de la duración y de la estancia. El instante percibido desde la obra de Vermeer es la sencillez de lo cotidiano, lo íntimo y lo vanamente singular. Vermeer ve el instante y logra su aislación mediante el arte silencioso de la luz difuminada en figuras, sombras, texturas y color. En el instante, el pintor ve la vida suspendida, la diferencia intrínseca a toda plenitud. Percibe al instante, que es fragmento de vida, precisamente como un "concentrado de eternidad". ${ }^{45}$

${ }^{43}$ Además de que su limitación cuantitativa la hacen un tanto más comprensible y aprehensible para nuestros propósitos.

${ }^{44}$ Lapoujade, op. cit., p. 275.

${ }^{45}$ Ibid., p. 220. 
Los instantes parecieran ser para Vermeer - como para Bergson, Bachelard o Xirau - duración e irrupción, brotamiento y continuidad, eternización de lo efímero, grandeza de lo pequeño, inmensidad en lo aparentemente minúsculo, microcosmos que acaecen en el tiempo macrocósmico y universal.

Cada cuadro de Vermeer en particular, y cada obra de arte en general, roba, como lo hace la memoria reverberante, un instante al tiempo; abre una ventana, lo muestra. Ocultando la sucesión del tiempo y la desmesura del mundo, la obra de arte des-oculta, desvela al instante y a todo su misterio ocultando otro tanto. La mirada del artista, su imaginación creadora, ilumina una irrupción, la tregua del movimiento físico y el comienzo de un juego donde resuena la duración de una danza de fuerzas capturadas instantáneamente.

Imaginar es gestar instantes suspensos del movimiento vertiginoso de la imaginación, reteniendo momentáneamente su fluir, dándole diversas configuraciones particulares: las imágenes [...] Las imágenes son "coagulaciones" de la imaginación. Son intervalos en que la fuerza de imaginar se concentra en puntos instantáneos. ${ }^{46}$

El artista creador, dueño de una sensibilidad prodigiosa, es sensible a las fuerzas que son el cosmos, el caos y la vida en su diversidad, por ello logra pintarlas y capturarlas por instantes.

El arte efectivamente lucha con el caos, pero para hacer que surja una visión que lo ilumine un instante, una Sensación. [...] El arte no es el caos, sino una composición del caos que da la visión o sensación, de tal modo que constituye un caosmos, como dice Joyce, un caos compuesto. ${ }^{47}$

Como si la obra nos quisiera decir que su esencia está en la concentración del instante, en esa aparente sencillez que permite apreciar las fuerzas contenidas de la vida y de las estancias humanas. Vermeer pintó la presencia de fuerzas deteniéndolas en la duración de una instantánea,

${ }^{46}$ Ibid., p. 42.

${ }^{47}$ Deleuze y Guattari, ¿Qué es la filosofía?, p. 205. 
pintó personas en su instancia, siendo plenamente en su mirada, su acto, volcando su vida en ese estar que es muchas veces nuestro quehacer cotidiano. Retratos de personas viviendo el instante, siendo ellas mismas fuerzas dentro del juego de fuerzas cósmicas, duración en la Duración, personas haciendo estancia que más que su "ser" se nos muestran desde el "estar".

Con Vermeer, vemos cómo en la obra de arte el instante se eterniza, entendemos la obra como una ventana que abre el tiempo, lo resquebraja y nos permite asomarnos a su núcleo de fuerzas en tensión.

Deleuze y Guattari explican que la obra de arte es un monumento erigido por el artista sobre la Tierra. Un monumento que logra "abrir o hendir, igualar lo infinito. Tal vez sea esto lo propio del arte, pasar por lo finito, para volver a encontrar, volver a dar lo infinito". ${ }^{48}$ Para Deleuze y Guattari, la obra de arte contiene fuerzas en juego que la sostienen con su poder intrínseco, porque en ellas se hacen sentir el caos y el orden cósmicos concentrados en una sola mirada (el caosmos: un cosmos caótico pero entrópico). Y dado que el Universo es infinito e infinitas son las combinaciones de las fuerzas y la materia en él, entonces: "Siempre harán falta otros artistas para hacer otras rasgaduras, llevar a cabo las destrucciones necesarias, quizá cada vez mayores, y volver a dar así a sus antecesores la incomunicable novedad que ya no se sabía ver". 49

La obra que captura las fuerzas ordena, ordena el caos, como lo hace el instante al reconfigurar la memoria. El artista percibe las fuerzas y las congrega, organiza y pinta las fuerzas haciendo rizoma con el mundo pues toma una parte de él y lo expande en otro territorio (como sucede con el ejemplo que vimos del pasto al ser trasplantado).

La obra es, entonces, un bloque de sensaciones, bloque de fuerzas que pueden ser sentidas pero nunca conceptualizadas y que transfigura al instante intempestivo y le extrae su duración. En este sentido, la obra logra poner a convivir, cohabitar, en un mismo sitio, finitud e infinitud, duración e instante; expresar materialmente fuerzas invisibles, componer novedades en el mundo que no pueden ser tomadas como copia

${ }^{48}$ Ibid., p. 165.

${ }^{49}$ Ibid., p. 205. 
ni reflejo de la realidad, sino las fuerzas mismas manifestándose de otro modo.

Siguiendo implícitamente la línea de Bachelard, Deleuze y Guattari dicen que la obra de arte es un átomo saturado, un germen, un instante capturado que es posibilidad e indeterminación. Y así, se entenderá que la obra de arte es una composición de fuerzas que quiere germinar, hacer rizoma, realizarse $\mathrm{y}$, como todo átomo saturado, cual huevo cósmico, quiere estallar y estalla en la mirada del espectador expectante.

La experiencia estética es entrar en un juego, zambullirse en el magma interno de la obra, una experiencia que encauza momentáneamente el continuo fluir y permite transitar los senderos ocultos del tiempo. La experiencia estética riega el germen que es la obra, fecunda el huevo, sobresatura el átomo, habita ese instante pintado obligando a las fuerzas ahí contenidas a detonarse.

La finalidad del arte, con los medios del material, consiste en arrancar el percepto de las percepciones de objeto y de los estados de un sujeto percibiente, en arrancar el afecto de las afecciones como paso de un estado a otro. Extraer un bloque de sensaciones, un mero ser de sensación. ${ }^{50}$

Al ser experimentada, la obra hace rizoma con quien se ha sumergido en ella y es así que su "material entra en la sensación", ${ }^{51}$ en el sentir de la persona que se demora ante ella. La obra "siempre añade variedades nuevas al mundo", 52 pues reconfigura las fuerzas y nuestras interpretaciones y preconcepciones de la realidad, identifica distintos instantes y los manifiesta siempre de forma inédita.

El artista visto así puede ser entendido como un persecutor y recreador de instantes gracias a su capacidad de imaginar y de ordenar las fuerzas, pero también al espectador y a cualquier persona que se detiene a reflexionar sobre sí misma, sobre su estancia, sus vivencias y sobre el tiempo propio y externo sobre el tiempo ya ganado o ya perdido. Borges señala que el hombre sumergido en la más divina de sus actividades, la

${ }^{50}$ Ibid., p. 168.

${ }^{51}$ Ibid., p. 175.

${ }^{52}$ Ibid., p. 167. 
de imaginar-soñar, tiene una experiencia como la que tendría un Dios omnividente "en un solo, espléndido, vertiginoso instante que es la eternidad", 53 que "a cada hombre le está dado, con el sueño, una pequeña eternidad personal", ${ }^{54}$ y quizá por ello, en la experiencia estética, cada persona se recrea desde la estancia abierta que la obra de arte abre como irrupción instantánea de la duración.

Hemos hablado aquí de la vida desde su duración, de la vivencia captada en el instante, del rasgo instantáneo de la eternidad; también hemos hablado de las obras que pintan las fuerzas desde la estancia y del artista que muestra, de formas múltiples y diversas, que todo puede ser dicho y amado con tan solo "la instantaneidad de una mirada", ${ }^{5}$

${ }^{53}$ Jorge Luis Borges, Siete noches, 2007, México, FCE, p. 37.

${ }^{54}$ Loc. cit.

${ }^{55}$ Lapoujade, op. cit., p. 268 
CITAM Derechos Reservados.

La reproducción total o parcial de este artículo se podrá hacer si el ITAM otorga la autorización previamente por escrito. 